\title{
Indulto a Fujimori: revisión de las conclusiones de la Junta médica
}

\section{Pardon of Fujimori: a review of the conclusions of the Medical Board}

Correspondencia

Aldo Vivar

avivar@prisma.org.pe

Recibido: 26/12/2017

Aprobado: 29/12/2017

Citar como: Vivar A. Indulto a Fujimori: revisión de las conclusiones de la Junta médica. Acta Med Peru. 2017;34(4):3434

\author{
Aldo Vivar ${ }^{1 a}$ \\ 1 Colegio Médico del Perú. Lima, Perú. CMP: № 20515 \\ a Médico Internista
}

\section{Sr. Editor:}

Como parte de sus atribuciones constitucionales (artículo 118, numeral 21) de conceder indultos y conmutar penas; el Presidente de la República concedió el indulto y derecho de Gracia al interno Alberto Fujimori horas antes de la navidad. La decisión debió sustentarse en la existencia de una enfermedad en grado tal que justificara la excarcelación para cumplir con un designio moral: atenuar un sufrimiento físico innecesario exacerbado por las condiciones carcelarias o permitir una muerte digna. Días antes se había filtrado en redes sociales y en la prensa un documento - negado originalmente por el Ministerio de Justicia- que consignaba las conclusiones de la junta médica penitenciaria que evaluó el estado de salud de Alberto Fujimori ${ }^{[1]}$. Este documento sirvió de sustento de la Resolución Suprema № 281-2017-JUS que otorgó los beneficios penitenciarios.

El informe posee tres conclusiones principales: la supuesta progresión de una lesión maligna -ya tratada- en la lengua, el pronóstico de dos enfermedades crónicas cardiovasculares y el daño que haría la prisión sobre el sistema inmune. Adicionalmente, una hernia de núcleo pulposo, un hipotiroidismo subclínico, un trastorno depresivo y una insuficiencia vascular periférica (sin especificar arterial o venosa). Al no conocerse más detalles que lo circulado en los medios el análisis y las reflexiones clínicas siguientes se basan en lo ya publicado.

El carcinoma epidermoide de la lengua de Fujimori, denominado "cáncer" por la prensa, fue extirpado hace 20 años ${ }^{[2]}$. El informe de la junta médica penitenciaria menciona las recidivas, pero omite la fecha de la última. Extirpado un carcinoma, puede aparecer una lesión premaligna (displasia) en los siguientes meses o años degeneración del tejido que no es cáncer, pero si no es tratada puede degenerar en ello-. Lo aconsejable es el seguimiento clínico para detectar y extirpar potenciales recurrencias (lesiones premalignas). Si el cáncer fue extirpado totalmente y no tuvo diseminación regional, su capacidad de daño es casi nula. Las recurrencias aparecen sobre todo dentro de los dos primeros años del evento primario y el seguimiento clínico cada 6 o 12 meses es suficiente. La sobrevida a 5 años del carcinoma epidermoide de lengua es buena, hasta en $83,5 \%{ }^{[3]}$. Por declaraciones de su médico tratante, el paciente Fujimori se consideraba libre de enfermedad neoplásica ${ }^{[4]}$

Las enfermedades cardiovasculares como la hipertensión arterial y la fibrilación auricular aumentan su incidencia con la edad y sus consecuencias, ligadas además a la existencia de otros factores de riesgo como la dislipidemia, tabaquismo o diabetes mellitus, pueden ser fatales: infarto del miocardio, enfermedades cerebrovasculares o enfermedad vascular periférica ${ }^{[5]}$. Por tener muchas veces una etiopatogenia común es muy difícil y se diría hasta imposible establecer el peso de cada uno de los factores de riesgo en el pronóstico clínico.

Lo que es claro es que sin tratamiento ambas enfermedades tienen naturaleza mortal y si no, secuelas permanentes. Actualmente, la hipertensión arterial se controla con medicamentos de fácil acceso cuya dosis y combinación puede ser hecha en la práctica ambulatoria con la salvedad particular que en los adultos mayores el incremento es mayor en la presión sistólica que la diastólica ${ }^{[6]}$. El control de la fibrilación auricular -arritmia crónica prevalente en el adulto mayor, hasta 5,9\% de la población ${ }^{[7]}$, se logra también con fármacos de fácil acceso y con un control periódico que puede incluir cada cierto tiempo la toma de un electrocardiograma. La consideración del uso de anticoagulantes para evitar una embolia utiliza escalas con datos simples (presencia de comorbilidades o insuficiencia cardíaca, edad, eventos embólicos previos). 
No se han encontrado estudios que demuestren que la carcelería per se empeore la progresión de estas enfermedades salvo que el reo consuma alcohol, tabaco o alimentos altos en sal o grasas. Un control periódico, dieta saludable, medicación efectiva son factores de riesgo modificables que favorecen el pronóstico ${ }^{[8]}$. Es de conocimiento público que Fujimori cuenta con médico de cabecera y que sus condiciones carcelarias eran mejores con respecto al promedio de la población penal del país.

El sistema inmune, un complejo y ordenado engranaje de células y macromoléculas, nos defiende de agentes patógenos, vigila y destruye células tumorales, así como modula la interacción que tenemos con las bacterias que viven dentro del cuerpo. Enfermedades como la diabetes, desnutrición severa, cirrosis, SIDA no tratado o insuficiencia renal deprimen algunos o todos los componentes de la inmunidad haciéndonos vulnerables a infecciones. No esta demostrado que las enfermedades psiquiátricas per se induzcan a mayor incidencia de infecciones y tumores ${ }^{[5]}$, las asociaciones estadísticas observadas en algunos estudios se deben a la concurrencia de malos estilos de vida o pobre acceso a servicios de salud.

La forma más severa de depresión es la depresión mayor y junto a la distimia pueden afectar significativamente la calidad de vida. Un encierro prolongado como la prisión lleva a formas reactivas que pueden controlarse con adecuada psicoterapia y técnicas de distracción como la jardinería y la pintura. Todas las formas de depresión se benefician del uso de antidepresivos escogidos por el tipo clínico y las comorbilidades. En este caso, la junta médica no tipificó el trastorno depresivo.

Una enfermedad terminal, se define como una condición clínica irreversible e incurable producto de una enfermedad sistémica y debilitante que lleva al paciente a la disminución o ausencia de la capacidad para realizar actividades cotidianas y a la postración pudiendo acompañarse o no de deterioro intelectual importante (incluyendo el estado vegetativo). El pronóstico de vida puede ser menor a seis meses. La definición de enfermedad grave no terminal no es de uso corriente en el ámbito clínico, la definición de "...en etapa avanzada, progresiva, degenerativa e incurable; y además que las condiciones carcelarias puedan colocar en grave riesgo su vida, salud e integridad." se puede interpretar como la ocurrencia de una enfermedad crónica cuya progresión y/o complicación la coloca en la condición de terminal (p. ej. insuficiencia renal crónica en diálisis permanente, fibrosis pulmonar con capacidad vital límite, cardiomiopatía dilatada con pobre fracción de eyección, etc.). De lo mencionado por la junta médica ninguna calificaría estrictamente como grave no terminal en el sentido del reglamento salvo una interpretación hiperbólica.

Por lo expuesto, preocupa la discordancia significativa entre las premisas y conclusiones esbozadas por la Junta médica penitenciaria, con "cabos sueltos" como falta de información clínica que permita que terceros la interpreten y lleguen a similares conclusiones. Es significativa la ausencia de un prolijo examen neurológico y psiquiátrico (por los diagnósticos consignados) y evaluación del sistema vascular periférico -se mencionan signos de congestión venosa central $[\mathrm{IY}+, \mathrm{RHY}+]$ pero aparecen sueltos en la exploración física sin un correlato clínico. Esta discordancia también se observa en las conclusiones del tratamiento que parecen ir en contra de la tendencia actual sobre el control ambulatorio de enfermedades cardiovasculares que, incluso en un adulto mayor, permite que miles de personas de similar edad con los mismos males del paciente Fujimori puedan gozar de años productivos y buena calidad de vida.

Mención aparte merece la conformación de la Junta médica cirujano oncólogo de cabeza y cuello, cardiólogo e intensivista-. Dadas las patologías múltiples consignadas, se extraña la omisión de otras especialidades como la de un médico internista, un oncólogo clínico o un psiquiatra que hubiesen ofrecido una visión integral de los problemas médicos del paciente. La RM № 0162-2010-JUS no limita el número de integrantes de la junta. Es llamativo que uno de los miembros de la junta sea el médico tratante del interno y por lo tanto tenga un conflicto de interés con la parte solicitante. La junta médica representa al Estado y como tal debe ser neutral, objetiva y justa.

Las conclusiones de esta Junta médica se alejan de un análisis clínico riguroso. Existen falencias en la correlación directa de los hallazgos clínicos con las evidencias científicas, donde los términos empleados como enfermedad grave no terminal, degenerativa e incurable no denotan una severidad clínica que requiera la hospitalización obligatoria y permanente o el uso frecuente e ineludible de equipos para mantener la vida.

El acto médico cualquiera sea el caso no debe escapar nunca de dos bases fundamentales, su rigurosidad científica y el cumplimento de las normas éticas. Los profesionales médicos que integraron la junta pueden ampararse en su libertad para pertenecer a ella, pero no deben olvidar que el ejercicio de la libertad conlleva una responsabilidad. En este caso la rendición de cuentas y la transparencia que como acto del Estado está sometido a escrutinio. Tal parece que en el informe de la junta médica del caso Fujimori, de acuerdo a la información hecha pública, no se habrían cumplido a cabalidad estos preceptos, por lo que su legitimidad profesional al menos es cuestionable, acaso factible de corrección o de una llamada de atención a sus integrantes por parte de las autoridades pertinentes.

\section{REFERENCIAS BIBLIOGRÁFICAS}

1. Alberto Fujimori: informe médico sobre indulto "no existe" para el Minjus. La República [Internet]. 21 Dic 2017 [citado el 9 de diciembre de 2017]. Disponible en: http://larepublica.pe/ politica/1160713-alberto-fujimori-minjus-precisa-que-pedido-deindulto-no-existe-para-el-sector

2. Kumar M, Nanavati R, Modi TG, Dobariya C. Oral cancer: etiology and risk factors: a review. J Cancer Res Ther. 2016;12(2):458-63.

3. La lengua del ex presidente Fujimori. El Comercio [Internet]. 21 Feb 2011 [citado el 9 de diciembre de 2017]. Disponible en: https:// elcomercio.pe/blog/cuidatusalud/2011/02/la-lengua-del-expresidente-fu

4. Rusthoven K, Ballonoff A, Raben D, Chen C. Poor prognosis in patients with stage I and II oral tongue squamous cell carcinoma. Cancer. 2008;112(2):345-51.

5. De Hert M, Correll CU, Bobes J, Cetkovich-Bakmas M, Cohen D, Asai I, et al. Physical illness in patients with severe mental disorders. I. Prevalence, impact of medications and disparities in health care. World Psychiatry. 2011;10(1):52-77.

6. Whelton PK, Carey RM, Aronow WS, Casey DE Jr, Collins KJ, Dennison Himmelfarb C, et al. 2017 ACC/AHA/AAPA/ABC/ACPM/ AGS/APhA/ASH/ASPC/NMA/PCNA Guideline for the Prevention, Detection, Evaluation, and Management of High Blood Pressure in Adults: Executive Summary: A Report of the American College of Cardiology/American Heart Association Task Force on Clinical Practice Guidelines. Hypertension. 2017 Nov 13. doi: 10.1161/ HYP. 0000000000000066 . [Epub ahead of print]

7. Franken RA, Rosa RF, Santos SCM. Atrial fibrillation in the elderly. J Geriatr Cardiol. 2012;9(2):91-100.

8. Thomas EH, Wang EA, Curry LA, Chen PG. Patients' experiences managing cardiovascular disease and risk factors in prison. Health Justice. 2016;4:4 